\title{
Legacies and Politics of Nuclear Power
}

\author{
Makiko Takemoto
}

\section{The World Before and After Fukushima}

This article serves as the introduction to the special issue "Legacies of Nuclear Power, Future of Nuclear Politics" of the Asian Journal of Peacebuilding. It aims to outline the background of the special issue and the significance of all articles: to think about the actual situation concerning nuclear issues.

The nuclear attacks on Hiroshima and Nagasaki on August 6 and 8, 1945 have a representative and symbolic meaning for the opening of the nuclear age. Although nuclear materials had already been discovered and used for medical purposes, the mushrooms clouds over Hiroshima and Nagasaki were powerful illustrations of the destructive potential and dangers of nuclear energy. Can nuclear materials help humanity with the energy deficit and fatal diseases like cancer? Or will they be utilized as weapons, leading to many other Hiroshimas and Nagasakis and become the destroyer of the world? How can human beings control nuclear energy?

The discussion on the international control of nuclear materials began before 1945. U.S. President Dwight Eisenhower's "Atoms for Peace" speech at the United Nations in 1953 accelerated the civilian use of nuclear energy. Exhibitions on the "peaceful use" of nuclear energy were held in many places, not only in the United States but also in West Germany and Japan in the 1950s. As the first and only country victimized by the military use of the atomic bombs, Japan became one of the most dedicated users of nuclear energy. The potential shortage of energy resources in Japan is one reason and the dependence of the conservative Japanese government on the United States was another important factor in Japan developing into a nuclear state. Moreover, many Japanese people wanted to use nuclear energy as a "peaceful" energy source because they comprehended the 
destructive force of nuclear energy and they hoped that nuclear energy would never be used to kill people; nuclear energy was to be used to promote peace.

With the intensification of the Cold War, nuclear weapons became a key source of military and political power. The Soviet Union, the United Kingdom, France, and China developed their own atomic bombs and the newly developed hydrogen bombs. After coming to the edge of nuclear war during such events as the Cuban Missile Crisis, the Treaty on the Non-Proliferation of Nuclear Weapons (NPT) was established in 1968. Until now, the NPT has played an important role in limiting nuclear proliferation, even though it has many significant systematic problems. As is well known, the NPT is an unfair treaty which is advantageous for the five nuclear states, the United States, the Soviet Union (Russia), the United Kingdom, France, and China. There is a loophole in the treaty; for example countries like India and Pakistan developed atomic bombs outside of the treaty and North Korean nuclear development is a significant problem. The treaty works only to "control" nuclear weapons, not to abolish them. Furthermore, the NPT actively promotes the civilian use of nuclear energy. Nuclear materials are controlled under the surveillance of the International Atomic Energy Agency (IAEA); however the treaty cannot abolish weapons nor power plants.

The belief that "peaceful" use of nuclear energy was safe started to collapse in the 1970s. Civil protests and social movements were intense and extensive in 1968 and they brought strong anti-nuclear power plant movements to countries such as West Germany and Austria. The anti-nuclear power plant movements were not only environmental movements but also peace movements in the broader sense, protest movements against the danger to life (Takemoto 2017). The Three Mile Island accident in 1979 and the Chernobyl disaster in 1986 made this even more explicit. At the same time, nuclear power plants built in the 1950s started to reach the end of their designed life span and decommissioning became a theme of discussion. The era of nuclear development had come to an end and the era of decommissioning had begun. The age of decommissions ushered in "the era of the endless keeping of nuclear materials such as accumulated plutonium and nuclear waste" (Wakao 2017).

The Fukushima incident on March 11, 2011 became a turning point in nuclear politics in some countries, to some extent. Germany decided to phase out its use of nuclear energy. However, the decision was the result of long discussions there rather than as a reaction to the Fukushima disaster. Germany had once decided to cease using nuclear energy under the coalition government led by the Social Democratic Party and the Green Party and it is a long-standing part of German protest culture. In Japan, the Fukushima incident brought new types of social movements. The anti-nuclear power plant demonstrations in front of the Prime Minister's residence every Friday is one of example. Especially in the field of historical and cultural studies, March 11, 2011 became an important break which brought a new perspective for research. However, in the field of politics, 
the influence of the incident is less remarkable. Many countries are still heavily dependent on nuclear energy. ${ }^{1}$ This gap between cultural phenomenon and real politics has yet to be filled.

\section{The Tangled Problems of Nuclear Politics}

This special issue consists of four articles on nuclear politics which are written by three Japanese scholars and one American researcher who is working in Hiroshima. The historical developments and the backgrounds of nuclear politics in the United States, France, Germany, and Finland are analyzed. They deal with legacies of the era of nuclear development and reflect on the new perspectives which came about after 2011.

The four studies explore a common problem-nuclear energy as an aspect of state power in the twentieth century. They make it clear that the "peaceful" use of nuclear energy and nuclear weapons are two sides of the same coin. The history of the development of nuclear energy reflects both the history of the development of technology and the history of the relationship and antagonism between human beings and their environment.

All nuclear power plants should be decommissioned when they reach the end of their life span. After almost seventy-five years of nuclear development, we are now living in the era of decommissioning. However, the best way to deal with nuclear waste is still unclear. In addition, the situation with nuclear weapons is again deteriorating. The Treaty of the Prohibition of Nuclear Weapons (the Nuclear Ban Treaty) of 2017 is an important treaty for eventually building a nuclear free world; however, nuclear states as well as countries under the nuclear umbrella like Japan and Germany do not support the treaty. As of June 1, 2018, there are still about 14,450 nuclear warheads in the world; 6,450 of them in the United States and another 6,850 in Russia. ${ }^{2}$ In Japan, the country which experienced nuclear attacks, the problem is understood as a "dilemma" in nuclear policy: the "dilemma" between nuclear abolition and nuclear deterrence (Suzuki 2017). The issues surrounding nuclear weapons are still often separated from the nuclear power plant issue. However, not only in the field of nuclear politics but also nuclear energy, there are other dilemmas. Nuclear power plants contribute enormous amounts of energy and at the same time they produce enormous amounts of nuclear waste. This can also seen as part of the "dilemma" (ibid.). Another issue in the nuclear dilemma is the production of plutonium in the nuclear fuel cycle and its role as a potential deterrent. Moreover, according to Suzuki, nuclear abolition, nuclear deterrence, and the nuclear fuel cycle are the "nuclear trilemma" (Suzuki 2019). Austria is a minority in this sense; both the nuclear power phase out and anti-nuclear weapon movement have been quite actively led by the government. Many countries are dependent on nuclear energy, 
and underdeveloped countries especially seek to develop nuclear energy for industry. The era of decommissioning has begun, yet most problems of nuclear energy remain unsolved.

This special issue provides a historical view to the debates around the nuclear issue. More case studies and further research is necessary. Hopefully the following articles will provide stimulus for the development of this research.

The first article, "Born Violent: The Origins of Nuclear Power" by Robert Jacobs, traces the history of the Hanford site. The development of the site, the earlier construction of the first reactor "Chicago Pile 1" (CP-1), and the experiments and the manufacturing of nuclear weapons are carefully examined. The Hanford site was part of the Manhattan Project, which developed the atomic bombs that were used on Hiroshima and Nagasaki, and a legendary site in the development of U.S. nuclear technology. Even though the Hanford site never experienced a nuclear plant meltdown, as Jacobs writes, "the very first nuclear power plant was built specifically to kill 100,000 people" and even if it is not used to manufacture nuclear weapons, it can still be fatal to human beings due to the risk of catastrophic incidents and damage to the environment. "Nuclear power plants were born violent" and "born to kill." This is a significant view for confronting the nuclear issue, because it has very often been ignored in order to promote the "peaceful" use of nuclear energy. His article contributes not only to the historiography of U.S. nuclear politics but also to the historical research of nuclear culture in the United States.

Chieko Kojima's article "France's Marcoule Nuclear Site: A History of Transition from Military to Civilian Use" examines the history of French nuclear politics. France has been the country most dependent on nuclear energy in the world. Kojima traces the development of nuclear technology in France from the beginning to the post Fukushima period. She focuses on the nuclear site "Marcoule" as a case study with an examination based on her own visit to the site. At Marcoule, the developments and changes in French nuclear politics are reflected, namely the changes from the research for the production of plutonium for military use to the research into nuclear fuel cycle and reactors, and then to the research for the disposal of spent nuclear fuel. Kojima's research presents not only a detailed and well-informed case study, it brings a historical view to French politics as well as a common theme of a nuclear site as a global issue, especially when it is compared with the Hanford case. In her article as well as Jacobs' study, it is also clear that the military use and civil use of nuclear power are part of the same process.

The article "The Legacies of the Uranium Mining Company 'Wismut' in East Germany" by Eiichi Kido focuses on a representative uranium mining company Wismut in East Germany. As the German and Austrian journalist Robert Jungk examined in his book Nuclear State in 1978, in a society that is dependent on nuclear power, information tends to be controlled and citizens are 
often under surveillance because nuclear politics are always kept secret. Wismut was the center of uranium mining and a "state within the state" in East Germany; therefore it was taboo to talk about it. As Kido explains in his introduction, only after the end of the Cold War did people start to deal with the problem of Wismut, especially in movies. There is still not enough research about Wismut and East German uranium mining. Kido's article examines not only the politics but also culture in the nuclear state and fills the gap in research about politics and daily life in the controlled, totalitarian, and socialist East German society and the role of nuclear energy for this society. Moreover, Kido's study implies that the "legacy" of Wismut should be regarded in the context of the nuclear issue in the wider world, namely, as a Global Hibakusha issue. Besides the hibakusha in Hiroshima and Nagasaki, there are many people who were exposed to radiation and also many potential hibakusha who live near nuclear sites in the world. The victims in Wismut should be understood as global hibakusha and it is necessary to consider nuclear issues as global issues for all people; not only in the field of politics and international relations, but also in terms of culture and the environment.

The articles by Kido and Kojima are mainly based on their own articles in Japanese which were published as the edited compilation Kaku kaihatsu jidai no isan - Mirai sekikin wo tou [The Legacy of the Era of Nuclear Development: Responsibility for the Future] in 2017 (Wakao and Kido 2017). As one of the editors, Yuji Wakao explained that this book aimed to examine the whole history of the nuclear era with case studies at the micro level (Wakao 2017). These kinds of detailed case studies seem to be becoming increasingly important in the push for the decommissioning of nuclear power plants.

Sato's article "Historical Background of Nuclear Waste Policy Formation in Finland and Comparison with (West) Germany" examines the background of nuclear waste policy in Finland in comparison with that in Germany. The influence of the Cold War and the willingness to convert the civilian use of nuclear power to military use shows the differences between the positions of these two countries in international relations. Finland, a small state with limited power, sought and found its position in international nuclear development and political antagonism and was aligned with the Soviet Union as a result, while West Germany became a strongly anti-communist country and had a relationship with United States. Sato pointed out the absence of an anti-nuclear movement in Finland, which was also very different from West Germany where the anti-nuclear power plant movement has widely developed. The influence of the anti-nuclear movement on nuclear politics should be more closely examined in the case of many more countries. 


\section{Acknowledgements}

This introduction and the following papers by Kido and Kojima are supported by Kaken-hi "Reisenki oubei ni okeru 'kaku no heiwa riyō' no hyōshō ni kansuru kenkyū" [Study on the Representation of the 'Peaceful Use of Atomic Energy' in the West during the Cold War] (15H03257) and "Hōshasen busshitsu no seiji bunka shi ni kansuru kokusai hikaku" [International Comparison on Political Cultural History of Radioactive Material] (18H00701).

Special thanks go to the publisher Showado for generously allowing the translation of the articles by Kido and Kojima. Also, thanks to the Japanese Journal of Northern European Studies for agreeing to the same for Sato's paper.

\section{Notes}

1. Examples of the share of nuclear power in electricity generation in 2017: France 71.6\%, Ukraine 55.1\%, Slovakia 54.0\%, Hungary 50.0\%, Belgium 49.9\%, Sweden 39.6\%, Slovenia 39.1\% Bulgaria 34.3\%, Switzerland 33.4\%, Finland 33.2\%, Czech Republic $33.1 \%$, Armenia 32.5\%, Republic of Korea 27.1\%, United States of America 20.0\%, United Kingdom 17.8\%, Russia 17.6\%, Germany 6.7\%, China 3.6\%, Japan 3.2\% (IAEA 2019). In Japan, most reactors are currently offline (JAIF 2019).

2. Global list of nuclear warheads as of June 1, 2018: Russia 6,850; United States 6,450; France 300; China 270; United Kingdom 215; Pakistan 140; India 120-130; Israel 80; and North Korea 10-20 (RECNA 2018).

\section{References}

IAEA (Internatinal Atomic Energy Agency). 2019. "Nuclear Share of Electricity Generation in 2017." https://pris.iaea.org/PRIS/WorldStatistics/NuclearShareofElectricityGenerat ion.aspx (accessed May 10, 2019).

JAIF (Japan Atomic Industrial Forum). 2019. https://www.jaif.or.jp/cms_admin/wpcontent/uploads/2019/05/jp-npps-operation190510_en.pdf (accessed May 10, 2019).

RECNA (Research Center for Nuclear Weapons Abolition, Nagasaki University). 2018. "Global List of Warheads." http://www.recna.nagasaki-u.ac.jp/recna/en-nwdata/list_ of_nuclear (accessed May 10, 2019).

Suzuki, Tatsujiro. 2017. Kakuheiki to genpatsu - nihon ga kakaeru "kaku" no jirenma [Nuclear Weapons and Nuclear Power Plants: The Dilemma of Nuclear Energy for Japan]. Tokyo: Iwanami shoten.

Suzuki, Tatsujiro. 2019. "Nihon no kaku no trirenma - kaku haizetsu, kaku yokushi, kakunen saikuru” [Japan's Nuclear Trilemma: Nuclear Abolition, Nuclear Deterrence and Nuclear Fuel Cycle]. In Heiwa eno tobira wo hiraku [Opening the Door to Peace], ed. Hiroshima Peace Institute (HPI) of Hiroshima City University, Booklet of Hiroshima Peace Institute, Vol.6, pg. 151-172. 
Takemoto, Makiko. 2017. Doitsu no heiwa shugi to heiwa undō - waimar kyōwakokuki kara 1980 nendai made [German Pacifism and Peace Movements: From the Weimar Republic to 1980s]. Kyoto: Horitsu Bunka Sha.

Wakao, Yuji, and Eiichi Kido, eds. 2017. Kaku kaihatsu jidai no isan - Mirai sekikin wo tou [The Legacy of the Era of Nuclear Development: Responsibility for the Future]. Kyoto: Showado.

Wakao, Yuji. 2017. "Kaku kaihatsu no doujidai wo tou" [Examining the Contemporary History of Nuclear Development]. In Kaku kaihatsu jidai no isan - Mirai sekikin wo tou [The Legacy of the Era of Nuclear Development: Responsibility for the Future], eds. Yuji Wakao and Eiichi Kido, i-xviii. Kyoto: Showado.

Makiko Takemoto is an Associate Professor at Hiroshima Peace Institute of Hiroshima City University. She studied history and politics at Senshu University in Japan and Carl von Ossietzky University Oldenburg in Germany. She specializes in German peace movements and pacifism in the twentieth century. Her recent research includes the publication of her first book Doitsu no heiwa shugi to heiwa undō - waimar kyōwakokuki kara 1980 nendai made [German Pacifism and Peace Movements: From the Weimar Republic to 1980s], Kyoto: Horitsu Bunka Sha, 2017. E-mail: takemoto@hiroshima-cu.ac.jp 
